\title{
Combination pharmacotherapy for the treatment of the overactive bladder syndrome: a new solution for an old problem?
}

\author{
Ahmed El-Zawahry ${ }^{1}$ (D) Diaa E. E. Rizk ${ }^{2}$ \\ Received: 29 July 2019 / Accepted: 5 September 2019/Published online: 12 November 2019 \\ (C) The International Urogynecological Association 2019
}

Overactive bladder syndrome (OAB) is a chronic urological condition that affects almost $20 \%$ of the population with a significant adverse impact on the quality of life. OAB may also have serious health consequences including mortality secondary to the increased risk of depression, falls and fractures. Thus far, the use of antimuscarinic therapy in $\mathrm{OAB}$ patients has been disappointing with reported compliance rates between $17 \%-35 \%$ after 2 years. Critical appraisal of novel pharmacological modalities for treatment of $\mathrm{OAB}$, therefore, remains a research priority.

Successful treatment of OAB requires proper clinical evaluation. In addition, patient counseling is important as compliance with treatment is instrumental in improving therapeutic efficacy. The treatment algorithm for OAB is a stepwise approach beginning with conservative measures [1] and ending with more invasive procedures.

Pharmacotherapy is frequently resorted to after the failure of conservative therapy or initially in appropriately selected patients. Antimuscarinics are commonly used; however, discontinuation rates are very high because of bothersome side effects or inadequate clinical response. To improve efficacy, providers may increase the dose of the drug [2], switch to a different antimuscarinic or try a combination of antimuscarinics to improve the therapeutic efficacy at the expense of producing higher rates of side effects [3].

The $\beta 3$-adrenergic receptor agonist mirabegron is another class of medication that has been in use since 2012 for treatment of $\mathrm{OAB}$ with similar clinical efficacy to antimuscarinics. Mirabegron acts through activation of the pre-junctional $\beta 3$ adrenoceptors of the urinary bladder.

Ahmed El-Zawahry

ahmed.elzawahry@utoledo.edu

1 The University of Toledo and Medical Science, 3000 Arlington Ave, Toledo, OH 43614, USA

2 College of Medicine and Medical Sciences, Arabian Gulf University, Manama, Bahrain
Treatment of $\mathrm{OAB}$ with $\beta 3$-adrenergic receptor agonists has gradually gained acceptance in recent years as most clinical trials showed a better pharmacological profile and improved patient compliance compared with antimuscarinics [4-6].

When pharmacotherapy of $\mathrm{OAB}$ with either antimuscarinics or $\beta 3$-adrenergic receptor agonists does not achieve satisfactory results, then the next line of treatment becomes more invasive or inconvenient with increased risks of complications [7, 8]. Invasive options include onabotulinumtoxin-A intradetrusor injection, sacral neuromodulation or posterior tibial nerve stimulation [8]. In May 2018, the FDA approved combination therapy of a $\beta 3$-adrenergic agonist and an antimuscarininc, solifenacin, as another pharmacological treatment option for OAB [9]. This may offer an additional promising non-invasive therapeutic management step between single-agent pharmacotherapy and more invasive approaches for the treatment for patients with $\mathrm{OAB}$.

The FDA decision was based on three seminal, multicenter and prospective randomized, double-blind, placebocontrolled trials, the SYMPHONY trial [10], BESIDE trial [11] and SYNERGY trial [12]. These demonstrated a significant improvement in urgency, urgency incontinence and other storage symptoms in the combination therapy arm compared with placebo or monotherapy. In all three studies, combination therapy was better tolerated with minimal side effects that were comparable to single drug treatment, and this was associated with improved quality of life. The adverse events reported with combination therapy were not significantly more bothersome than with monotherapy $[10,12]$. This effect continues to be demonstrated in the elderly population.

In conclusion, the FDA approval of combined drug therapy has expanded our pharmacological armamentarium in monotherapy-refractory $\mathrm{OAB}$ before considering invasive procedures. The combination drug has a different pharmacological profile and seems to be safer and better tolerated by patients than a combination of two drugs from the same class. Until more clinical data are available, we believe that combining anticholinergics with a $\beta 3$-adrenergic receptor agonist is a good pharmacotherapy option for OAB patients who failed 
monotherapy and may be an appropriate step before moving on to more invasive or inconvenient therapeutic options. The future will tell if there will be a new therapy that will contain the combination therapy in one pill form and if insurance coverage will be expanded to cover this combination therapy.

\section{Compliance with ethical standards}

Conflict of interest None.

\section{References}

1. Monteiro S, Riccetto C, Araujo A, Galo L, Brito N, Botelho S. Efficacy of pelvic floor muscle training in women with overactive bladder syndrome: a systematic review. Int Urogynecol J. 2018;29(11):1565-73. https://doi.org/10.1007/s00192-018-3602-x.

2. Goldman HB, Oelke M, Kaplan SA, Kitta T, Russell D, Carlsson $\mathrm{M}$, et al. Do patient characteristics predict which patients with overactive bladder benefit from a higher fesoterodine dose? Int Urogynecol J. 2019;30(2):239-44. https://doi.org/10.1007/ s00192-018-3640-4.

3. Wang CC, Jiang YH, Kuo HC. Efficacy and adherence of flexibly adding on a second antimuscarinic agent for patients with refractory overactive bladder. Low Urin Tract Symptoms. 2017;9(1):27-32. https://doi.org/10.1111/luts.12103.

4. Hsu FC, Weeks CE, Selph SS, Blazina I, Holmes RS, McDonagh MS. Updating the evidence on drugs to treat overactive bladder: a systematic review. Int Urogynecol J. 2019. https://doi.org/10.1007/ s00192-019-04022-8.

5. Kelleher C, Hakimi Z, Zur R, Siddiqui E, Maman K, Aballea S, et al. Efficacy and tolerability of mirabegron compared with antimuscarinic monotherapy or combination therapies for overactive bladder: a systematic review and network meta-analysis. Eur Urol. 2018;74(3):324-33. https://doi.org/10.1016/j.eururo.2018. 03.020 .

6. Staskin D, Herschorn S, Fialkov J, Tu LM, Walsh T, Schermer CR. A prospective, double-blind, randomized, two-period crossover, multicenter study to evaluate tolerability and patient preference between mirabegron and tolterodine in patients with overactive bladder (PREFER study). Int Urogynecol J. 2018;29(2):273-83. https:// doi.org/10.1007/s00192-017-3377-5.

7. Elmer-Lyon CG, Streit JA, Takacs EB, Ten Eyck PP, Bradley CS. Urinary tract infection and drug-resistant urinary tract infection after intradetrusor onabotulinumtoxinA injection versus sacral neuromodulation. Int Urogynecol J. 2019. https://doi.org/10.1007/ s00192-019-04007-7.

8. Iyer S, Laus K, Rugino A, Botros C, Lozo S, Botros SM, et al. Subjective and objective responses to PTNS and predictors for success: a retrospective cohort study of percutaneous tibial nerve stimulation for overactive bladder. Int Urogynecol J. 2019;30(8):12539. https://doi.org/10.1007/s00192-018-3822-0.

9. FDA Approves Mirabegron, Solifenacin Combo for OAB. http:// fdadaily.com/2018/05/09/fda-approves-mirabegron-solifenacincombo-for-oab/. 2018. Accessed 7/15/2019.

10. Abrams P, Kelleher C, Staskin D, Kay R, Martan A, Mincik I, et al. Combination treatment with mirabegron and solifenacin in patients with overactive bladder: exploratory responder analyses of efficacy and evaluation of patient-reported outcomes from a randomized, double-blind, factorial, dose-ranging, phase II study (SYMPHONY). World J Urol. 2017;35(5):827-38. https://doi. org/10.1007/s00345-016-1908-1.

11. Drake MJ, Chapple C, Esen AA, Athanasiou S, Cambronero J, Mitcheson D, et al. Efficacy and safety of mirabegron add-on therapy to solifenacin in incontinent overactive bladder patients with an inadequate response to initial 4-week solifenacin monotherapy: a randomised double-blind multicentre phase 3B study (BESIDE). Eur Urol. 2016;70(1):136-45. https://doi.org/10.1016/j.eururo. 2016.02.030.

12. Herschorn S, Chapple CR, Abrams P, Arlandis S, Mitcheson D, Lee $\mathrm{KS}$, et al. Efficacy and safety of combinations of mirabegron and solifenacin compared with monotherapy and placebo in patients with overactive bladder (SYNERGY study). BJU Int. 2017;120(4):562-75. https://doi.org/10.1111/bju.13882.

Publisher's note Springer Nature remains neutral with regard to jurisdictional claims in published maps and institutional affiliations. 